\title{
Trabalho e emprego na educação infantil no Brasil: segmentações e desigualdades
}

\section{Labor and employment in early childhood education in Brazil: cleavages and inequalities}

\author{
Lívia Fraga Vieira ${ }^{1}$ \\ Gizele de Souza ${ }^{2}$
}

\begin{abstract}
RESUMO
Objetiva-se trazer resultados de pesquisa empírica sobre situações de trabalho e emprego nas instituições de educação infantil no Brasil, evidenciando o caso de Belo Horizonte, capital de Minas Gerais, que apresenta oferta em creches e pré-escolas, representativa da realidade dos grandes centros urbanos brasileiros. Efetuou-se o levantamento de fontes documentais, legislação, estatísticas, entrevistas e observações, no intuito de evidenciar as relações entre as tipologias das instituições de educação infantil e as formas de contratação, carreira, salário e condições de trabalho. As situações investigadas se referiram aos estabelecimentos de ensino público (estadual e municipal) e estabelecimentos de ensino privados, segundo as categorias particular, comunitária, filantrópica e confessional. Os estabelecimentos estudados foram escolhidos, segundo amostra intencional, por localização e público preferencial atendido. Informações também foram buscadas junto aos empregadores - públicos e privados e junto às representações sindicais/associativas dos profissionais, nos setores públicos e privados. Evidenciou-se existência de profissionais com status e formação/qualificação diferenciados, bem como variadas modalidades de relações de emprego
\end{abstract}

1 Doutora em Sociologia. Professora da graduação e do programa de pós-graduação da Faculdade de Educação da Universidade Federal de Minas Gerais (UFMG) - Brasil. Associada ao Grupo de Pesquisa sobre Política Educacional e Trabalho Docente - GESTRADO e do Núcleo de Estudos sobre Infância e Educação Infantil - NEPEI, ambos da UFMG. E-mail: liviafraga@globo.com

2 Doutora em Educação. Professora do Setor de Educação e do Programa de Pós-Graduação em educação da Universidade Federal do Paraná (UFPR) - Brasil. Coordenadora do NEPIE Núcleo de Estudos e Pesquisas em Infância e Educação Infantil, na mesma universidade. E-mail: gizelesouza@uol.com.br 
e trabalho, que revelam processo de precarização no exercício profissional na educação infantil. Segmentações no interior do setor público, e entre setor público e privado, reiteram desigualdades históricas no campo. Por outro lado, uma demanda crescente por profissionalização é observada. Palavras-chave: trabalho docente; situação trabalhista; educação infantil; educação pré-escolar.

\begin{abstract}
The present work aims at presenting results of empirical research about the situations of labor and employment in institutions of child education in Brazil, highlighting the case of Belo Horizonte, Capital city ofMinas Gerais State, which offers nurseries and preschools and it is representative of Brazilian urban centers. An analysis including documental sources, legislation, statistics, interviews and observations was conducted, aiming at revealing the relations between the typologies of child education establishments and the forms of recruitment, career, salary and working conditions. The situations examined referred to public education institutions (State and Municipal) and private institutions, according to the categories private, communitarian, philanthropic and confessional. The studied establishments were selected, through an intentional sampling procedure, based on location and preferential public attended. Information was also collected from employers - public and private - and from representations of the unions/associations of professionals, in the public and private sectors. The existence of professionals with differentiated status and formation/ qualification was evident, as well as a number of modalities of labor and work relations, which reveal a process of precariousness in the professional exercise in child education. Cleavages within the public sector and between public and private sectors reiterate historical inequalities in that field. However, an increased demand for professionalization is observed. Keywords: teaching labor; employment situation; child education; preschool education.
\end{abstract}

\title{
Primeiras questões
}

Estudos e pesquisas atuais sobre trabalho docente no Brasil e na América Latina têm analisado as mudanças na sua organização e gestão, decorrentes de reformas educacionais iniciadas nos anos 1990. Observam-se a incorporação 
de novas funções e postos de trabalho, bem como a existência de processos de precarização cujos reflexos se expressam não apenas na formação, carreira e salários, mas também no status social e na identidade dos professores (BALL, 2002; TARDIF; LESSARD, 2007; FANFANI, 2005; OLIVEIRA, 2004). Embora sendo referência na área, essas pesquisas abordam de forma insuficiente o trabalho docente na educação infantil ${ }^{3}$, cujo recente processo de institucionalização no âmbito da educação básica ${ }^{4}$ brasileira tem requerido a necessidade de ampliar a reflexão e os conhecimentos, buscando a construção de um diálogo com pesquisas dentro de marcos mais amplos sobre a constituição dos sistemas de ensino na contemporaneidade.

No Brasil, conhecemos muito pouco sobre o trabalho e o emprego na educação infantil nos estabelecimentos públicos e privados de ensino. Embora exista uma produção acadêmica relativamente abundante sobre as condições de trabalho e emprego dos trabalhadores em educação no ensino fundamental e médio, pouco se sabe sobre as condições de trabalho em instituições de educação infantil, sobretudo porque nesta etapa da educação básica há uma grande variedade de situações e instituições que respondem pelo atendimento tanto público quanto privado. No que se refere aos trabalhadores da educação infantil, as pesquisas nos últimos anos têm se dedicado, desde meados dos anos 1990, mais ao tema da formação e identidade dos educadores/professores, e ainda carecemos de estudos abrangentes sobre o estatuto profissional e o trabalho nas creches e pré-escolas no Brasil. Com efeito, nós não possuímos estudos na área que permitam conclusões mais amplas sobre quem trabalha (perfil sociodemográfico), incluindo onde trabalha, sobre sua situação funcional e trabalhista, a sua formação ou sobre as categorias de trabalhadores/profissionais e requisitos para ingresso, contratação, formação, carreiras, renda e salário.

3 De acordo com a Constituição Federal de 1988 e a Lei de Diretrizes e Bases da Educação Nacional -LDBEN de 1996, educação infantil designa a frequência regular a um estabelecimento educativo exterior ao domicílio familiar por crianças que não estão submetidas à obrigatoriedade escolar. É oferecida em creches (crianças até três anos de idade) e em pré-escolas (crianças de quatro até seis anos), públicas ou privadas. Centro ou Unidade de Educação Infantil é também nomenclatura usada para designar serviços educacionais na área. Recentemente, a Constituição Federal foi alterada estendendo a obrigatoriedade escolar para crianças a partir de 4 anos de idade, abrangendo, portanto, a pré-escola. Esse dispositivo deverá ser progressivamente implementado a partir de 2011.

4 A Educação Básica é um nível de ensino dividido em 3 grandes etapas regulares: educação infantil (crianças de 0 a 5 anos), ensino fundamental (crianças de 6 a 14 anos) e ensino médio (jovens de 15 a 18 anos). Consideram-se também na educação básica as modalidades de ensino: educação especial, educação de jovens e adultos e educação profissional. 
No entanto, a educação infantil é um campo de trabalho e emprego de grandes dimensões, especialmente nas capitais dos 27 estados brasileiros e centros urbanos maiores, entre os mais de 5.500 municípios, e tem significado muitas vezes a porta de entrada de contrato de trabalho em diferentes contextos, sejam públicos ou privados.

As mudanças mais recentes na política educacional brasileira no que se refere ao acesso à educação básica têm ensejado maior cobertura do atendimento pelo poder público da população de zero a seis anos. O crescimento da matrícula nessa etapa da educação básica, embora seja mais significativo na última década, é um processo que se iniciou nos anos $1980 \mathrm{com}$ as creches comunitárias e pré-escolas públicas, vinculadas às áreas da saúde, assistência social ou da educação.

O município, na Lei de Diretrizes e Bases da Educação Nacional LDBEN, de 1996, foi diretamente responsabilizado pela oferta da educação infantil. Com efeito, acompanhando as características nacionais, na década de 1990, o que se observou foi uma crescente municipalização da pré-escola, seja pela transferência das matrículas [e escolas] das redes estaduais para os municípios, seja pela ampliação da demanda e a crescente responsabilização da esfera local de governo no plano da legislação. Tornou-se, então, dominante a participação dos municípios na oferta desta etapa da educação, coexistindo com nova conceituação de educação infantil, como primeira etapa da educação básica e como direito social da criança. O processo de municipalização é facilmente constatado nas estatísticas educacionais, as quais historicamente acumularam, desde os anos 1980, informações concernentes às pré-escolas, ou seja, ao atendimento das crianças de quatro a seis anos de idade. Em 1980, os municípios eram responsáveis por $29 \%$ das matrículas da pré-escola, passando a 75\% em 2008 (BRASIL, 2009a, 2009b). As informações educacionais relativas às creches ou às crianças de zero a três anos começaram a ser divulgadas pelo Instituto Nacional de Pesquisas Educacionais - INEP/MEC somente a partir de 1998 , permitindo saber que atualmente $65 \%$ das matrículas em creches são também municipais (BRASIL, 2009).

De uma oferta privada, persistente na década dos 1980, transitamos para a preponderância da iniciativa pública, por meio da oferta municipal nos anos 2000, sob responsabilidade das secretarias ou departamentos de educação. Estatísticas ministeriais informam que $74 \%$ das matrículas na educação infantil são públicas (BRASIL, 2008). Nos municípios, uma oferta de creches e pré-escolas públicas, existentes por meio da ação direta dos governos locais, construindo ou adaptando prédios, contratando ou realizando concursos para provimento de postos de trabalho na área, combina-se com outra modalidade de oferta por meio de convênios com as creches comunitárias e filantrópicas, 
na qual há repasse de recursos públicos para a sua manutenção. $\mathrm{O}$ modo como esta modalidade se efetiva e opera nas relações com as prefeituras é temática oportuna para a pesquisa educacional.

Pela preponderância da ação dos governos municipais, é nos estabelecimentos de ensino das administrações locais que estão concentrados os trabalhadores dessa etapa da educação básica. Mas é também relevante a oferta privada de educação infantil, perfazendo $26 \%$ das matrículas informadas em 2009, disponibilizando assim postos de trabalho na área.

A título de exemplo segue tabela abaixo demonstrativa da matrícula na educação infantil no período de 1997 a 2007. Na faixa da pré-escola o atendimento na rede pública cresceu em 18\% no período de 1997 a 2007, sendo a participação federal pequena; as redes estaduais diminuíram sua participação na oferta desde a aprovação da Emenda Constitucional n. 14, em $72 \%$, e as redes municipais aumentaram a matrícula em $38 \%$. Vale destacar que o setor municipal, em 1997, já respondia por mais de $60 \%$ da matrícula na faixa etária da pré-escola também.

TABELA 1 - MATRÍCULA NA EDUCAÇ̃̃O INFANTIL, BRASIL, 1997-2007

\begin{tabular}{l|r|r|r}
\hline Dependência administrativa & \multicolumn{1}{c|}{1997} & \multicolumn{1}{c|}{2007} & \% de cresc. \\
\hline Creche & 348.012 & 1.579 .581 & 354 \\
Pública & $\mathbf{2 3 3 . 4 0 0}$ & $\mathbf{1 . 0 5 0 . 2 9 5}$ & $\mathbf{3 5 0}$ \\
Federal & 387 & 974 & 152 \\
Estadual & 16.349 & 8.651 & -47 \\
Municipal & 216.664 & 1.040 .670 & 380 \\
Privada & $\mathbf{1 1 4 . 6 1 2}$ & $\mathbf{5 2 9 . 2 8 6}$ & $\mathbf{3 6 2}$ \\
Pré-escola & 4.292 .208 & 4.930 .287 & 15 \\
Pública & $\mathbf{3 . 3 0 4 . 7 7 6}$ & $\mathbf{3 . 8 9 8 . 0 9 5}$ & $\mathbf{1 8}$ \\
Federal & 2.025 & 1.167 & -42 \\
Estadual & 606.858 & 168.994 & -72 \\
Municipal & 2.695 .893 & 3.727 .934 & 38 \\
Privada & $\mathbf{9 8 7 . 4 3 2}$ & $\mathbf{1 . 0 3 2 . 1 9 2}$ & $\mathbf{5}$ \\
\hline
\end{tabular}

FONTE: INEP/MEC. Censo Escolar. Sinopse estatística 1997; 2007.

As definições atuais da educação infantil - que articulam, tornam complementares e indissociáveis as funções de cuidar e educar - resultam em novas exigências de formação, de qualificação, novas identidades profissionais e na discussão das carreiras, da profissionalização, da valorização e dos custos do trabalho docente na educação infantil, nos sistemas educacionais. 
A análise de pesquisas sobre políticas municipais no país, realizadas no período de 1996 a 2008 (VIEIRA, 2009), assim como os resultados de debates que ocorrem em fóruns e encontros da área revelam algumas tensões políticas relacionadas: ao estatuto profissional atribuído ao professor/educador infantil e aos seus "auxiliares" nas redes de ensino; à inclusão da criança de zero a três anos nos programas de oferta pública de creches municipais diretas, acarretando a demanda de um novo perfil dos profissionais que articule o cuidado e a educação; à administração do atendimento às crianças em jornada de tempo integral, que gera desafios para a gestão do cuidado/educação e para a organização do trabalho docente nas instituições educacionais. Tais tensões ganharam visibilidade no contexto nacional com o surgimento de novo movimento social pela efetivação dos direitos da criança, o Movimento Inter-Fóruns de Educação Infantil - MIEIB, que articula os fóruns dos 27 estados brasileiros, promovendo encontros e acompanhando a implementação das políticas municipais na área.

O objetivo deste artigo é trazer alguns resultados de pesquisa empírica sobre as situações de trabalho na área, realizada em Belo Horizonte, capital de Minas Gerais (VIEIRA et al., 2009) à luz de alguns dados estatísticos nacionais sobre condições de trabalho e emprego dos profissionais de educação infantil. Esta capital apresenta atendimento em creches e pré-escolas representativo da realidade dos grandes centros urbanos no país. Além disso, é constatada uma linha de continuidade das políticas públicas na educação e assistência social, setores que mais de perto estão implicados no campo de estudos aqui propostos, nos sucessivos governos municipais desde 1993.

A investigação buscou conhecer as situações de trabalho e emprego existentes por meio de levantamento de fontes documentais junto à Prefeitura de Belo Horizonte, incluindo legislação, estatísticas, entrevistas e observações. Procuramos evidenciar as relações entre as tipologias das instituições de educação infantil e as formas de contratação, carreira, salário, condições de trabalho e modos de organização do trabalho docente na educação infantil. As situações investigadas se referiram às tipologias de atendimento encontradas na educação infantil, tais como: estabelecimentos de ensino público estadual e municipal (de acordo com as nomenclaturas e modalidades existentes); estabelecimentos de ensino privados segundo categorias constantes na LDBEN/1996: particular, comunitária, filantrópica e confessional. Os estabelecimentos foram escolhidos compondo amostra intencional, segundo a localização e o público preferencial atendido ${ }^{5}$. Informações

5 Tomando como fonte o acervo dos convênios e das instituições particulares autorizadas, localizados em duas gerências específicas da Secretaria Municipal de Educação, foram pesquisadas 27 instituições em cada acervo, localizadas nas nove regiões administrativas da cidade. As instituições conveniadas foram escolhidas em função do número de crianças atendidas e montante de recursos repassados pelo poder público municipal. As particulares foram escolhidas apenas em função do número de crianças atendidas. 
também foram buscadas junto aos empregadores - públicos e privados e junto às representações sindicais/associativas dos profissionais que atuam na educação infantil, nos setores públicos e privados, nas diferentes categorias acima referidas.

Inicialmente buscamos contextualizar o tema no âmbito da política educacional, trazendo também informações sobre a composição da força de trabalho na área, para apresentar a discussão e os resultados da pesquisa.

\section{Organização, composição da força de trabalho e condições de trabalho na educação infantil no Brasil}

A estruturação da força de trabalho na educação infantil reflete a estruturação histórica dos serviços voltados para o cuidado e a educação da criança pequena, os quais se relacionam com as tradições (e inovações) socioculturais e com os modelos de organização das políticas sociais. Tais modelos estabelecem relação com as concepções do papel do Estado, da família e da sociedade na provisão de serviços de atenção à infância, no âmbito das políticas educacionais e assistenciais. Assim é que o entendimento do trabalho docente na educação infantil requer uma abordagem histórica das políticas de atendimento e das legislações concernentes. No Brasil, as políticas que visaram à expansão da oferta de creches e pré-escolas iniciadas no final dos anos de 1970, articuladas com as mudanças sociodemográficas das famílias, com a crescente inserção das mulheres no mercado de trabalho e com as demandas sociais por atendimento, conformaram determinado padrão dominante de organização dos serviços voltados para as crianças pequenas, baseado em precárias condições de trabalho e precário profissionalismo (VIEIRA, 1999; ROSEMBERG, 1999; 2002).

Em estudo comparado entre os 30 países vinculados à Organização para a Cooperação e o Desenvolvimento Econômicos - OCDE, Peter Moss (2006) observou duas grandes tendências de organização de serviços não domésticos, em espaços coletivos, visando o cuidado e a educação da criança pequena. Uma das tendências seria a de dividir os serviços entre um sistema vinculado ao bem-estar social ou assistência social e outro vinculado à educação. Nesse sistema, em geral as instituições de "cuidado" se vinculam à área do bem-estar destinadas às crianças menores que 3 anos de idade. A "educação" integra-se à administração educacional voltada para crianças com idade maior que 3 anos. Outra tendência constatada, presente em países nórdicos, caracteriza-se pela inserção das instituições nos sistemas de ensino, adotando uma abordagem integrada entre "cuidado" e "educação", para crianças de 0 a 6 anos. 
O referido autor mostrou que os modelos de organização dos serviços e do trabalho, a sua dependência administrativa e as suas origens históricas acarretam implicações em relação à formação, aos salários, às condições de trabalho e status profissional dos trabalhadores envolvidos.

Além disso, Peter Moss argumenta que a formação dos trabalhadores e a estrutura da força de trabalho na área não estão separadas dos entendimentos, das concepções sobre o trabalho e sobre os trabalhadores que se ocupam diretamente do cuidado e educação nas instituições de educação infantil.

Estudando as estratégias de expansão da educação infantil no Brasil, adotadas pelas políticas públicas a partir dos anos 1980, Fúlvia Rosemberg (1999) buscou evidenciar o padrão dominante e as concepções que sustentaram tais estratégias, destacando dois processos discriminatórios: (a) crianças negras e nordestinas (e pobres), com idade superior a 6 anos, retidas na pré-escola, segundo critérios estabelecidos nos sistemas de ensino, que só permitiam o acesso ao ensino fundamental obrigatório se essa criança já soubesse ler e escrever e (b) professoras leigas, mulheres das classes populares, arcando com a expansão das matrículas. A autora argumentava que as hierarquias de gênero interagem com as de raça e classe para produzir sistema educacional excludente no Brasil. Pressupunha que os sistemas educacionais são, simultaneamente, instâncias de formação de crianças, adolescentes, jovens e adultos e mercado de trabalho (para serviçais, docentes e técnicos), que produzem e reproduzem relações de gênero.

O modelo dominante de expansão da educação infantil, para a oferta pública ou subvencionada com recursos públicos, a oferta conveniada, foi resumidamente definido por Rosemberg (1999) como "modelo de massa a baixo custo apoiado em habilidades naturais de mulheres para cuidar de criança pequena". Baseava-se, portanto, numa concepção de que para ser "educadora" bastava ser mulher, apresentar habilidades maternas e gostar de criança. Assim, a mulher estaria naturalmente apta para reproduzir no âmbito coletivo os atributos e as atividades do trabalho doméstico requerido na criação dos filhos.

Nesse modelo, apelava-se para a participação das comunidades pobres e para a mobilização de recursos físicos e materiais locais ("espaços ociosos" e "sucatas"), legitimando-se duas trajetórias paralelas de educação infantil: uma que foi denominada de profissional, baseada na formação educacional do corpo docente, envolvendo espaços e equipamentos específicos nos sistemas de ensino; outra que se chamou de doméstica-familiar, apoiando-se nos recursos disponíveis da "comunidade" e no trabalho de educadoras de creches ou classes pré-escolares comunitárias, das quais se requeriam apenas capacitação esporádica e ligeira. Assim, paralelamente ao crescimento das matrículas iniciais na pré-escola, observado nos anos 1980, ocorreu aumento de educadoras/ professoras sem formação sustentando essa expansão, conclui a referida autora. 
A expansão ou massificação ocorreu tanto "dentro" quanto "fora" dos sistemas de ensino, neste caso, por meio de políticas subsidiadas pela área da assistência social, nas quais se privilegiou a modalidade do conveniamento, que se sustentou no trabalho precário de mulheres das classes populares ${ }^{6}$.

Maria Malta Campos (1994) mostrou também como historicamente se foram constituindo, de forma não integrada, o profissional que "cuida", em creches, cujo objetivo é (ou era) mais garantir um lugar seguro e limpo onde as crianças passam o dia, e o profissional que "educa", a professora, em pré-escolas, onde o objetivo mais proeminente, considerado "pedagógico", tem sido o de preparar a criança no ingresso do ensino fundamental. Constatou-se igualmente que essas duas concepções dos serviços de atendimento da criança de 0 a 6 anos, conhecidas como "assistencial" e "educacional", estavam em geral voltados para crianças de origens sociais diferentes: "as pobres, mais provavelmente, freqüentam um serviço 'assistencial', enquanto outras de classe média são atendidas em serviço "educacional"" (CAMPOS, 1994, p. 35). Essa autora nos fala que a moderna noção de cuidado busca superar essas dicotomias. Ela tem sido usada para "incluir todas as atividades ligadas à proteção e apoio necessárias ao cotidiano de qualquer criança: alimentar, lavar, trocar, curar, proteger, consolar, enfim, "cuidar"' (CAMPOS, 1994, p. 35), naquilo que usualmente chamamos de "educar". Assim,

[...] não só todos esses aspectos são recuperados e reintegrados aos objetivos educacionais, como também deixam de ser considerados como exclusivamente necessários à parcela mais pobre da população infantil, e de ser contemplados somente para as crianças menores de 2 ou 3 anos de idade. Todas as crianças possuem estas necessidades e, se todas têm o direito à educação, qualquer instituição que as atenda deve levá-las em conta ao definir seus objetivos e seu currículo (CAMPOS, 1994, p. 35).

Uma formação de professores(as) que contemple essa perspectiva integrada tem sido constantemente problematizada nas pesquisas sobre o tema nos últimos anos, tendo em vista que historicamente os cursos de magistério de nível médio não correspondiam a essa perspectiva e que a formação em nível de ensino superior era praticamente inexistente até meados dos anos 1990.

6 A referência mais significativa nessa área é o Projeto Casulo da antiga Legião Brasileira de Assistência (LBA), órgão responsável pela assistência social brasileira, criado em 1942 e extinto em 1995. Veja-se a respeito: Vieira (1986). As ações relativas às creches continuaram, no entanto, no âmbito ministerial, na alçada do Ministério da Previdência e Assistência Social, do Governo Fernando Henrique Cardoso. Recentemente, no Governo Lula, as ações relativas às creches foram definitivamente repassadas para o Ministério da Educação, saindo do poder do Ministério de Desenvolvimento Social e Combate à Fome. 
Além disso, há nessas discussões e nas propostas de formação docente que estão sendo implementadas (SILVA, 2001, 2007) questões que se relacionam com a identidade profissional dos trabalhadores envolvidos na educação infantil vinculados às diferentes tradições do atendimento, como se buscou mostrar anteriormente.

No Brasil, principalmente nos últimos 30 anos, dois setores da administração pública - nos planos municipal, estadual e federal - se ocuparam (e se ocupam) da oferta de educação infantil, compartilhando ou disputando atribuições e recursos, mobilizando pessoal com diferentes status e qualificação profissionais. A Assistência Social (com as creches e as pré-escolas) e a Educação (com as pré-escolas). A Assistência Social atuando sobretudo como instigadora de uma oferta organizada por entidades sociais de origem filantrópica ou comunitária, ocupando-se das creches coletivas, que atendiam crianças na extensa faixa etária de 0 a 6 anos (concentrando-se nas de 4 a 6 anos) e em regimes de tempo integral e parcial, com "educadoras" leigas, sem definição de carreiras ou status profissional. Instituiu também a modalidade de financiamento que privilegiou o convênio - repasse de recursos públicos para tais entidades não governamentais, desde 1977, ano em que foi implantado o "Projeto Casulo". Já a Educação tem se ocupado tradicionalmente, conforme tendência nacional, pela oferta da pré-escola pública, funcionando em regime de tempo parcial para crianças de 4 a 6 anos, por meio da criação dos jardins de infância (ou escolas infantis) ${ }^{7}$ e da implantação de classes pré-primárias ou pré-escolares nas escolas de ensino fundamental, no âmbito dos sistemas estaduais ou das redes municipais de ensino, acionando professoras com formação em magistério, de nível médio. Programas de expansão coordenados pela área educacional também mobilizaram "monitoras" sem tal formação mínima, nos anos $1980^{8}$.

Com tal herança, desde o final dos anos 1990, os municípios têm enfrentado os desafios de integrar esses estabelecimentos aos sistemas de ensino, estaduais ou municipais, aproximando-se ou distanciando-se do marco regulatório normativo inaugurado com a inserção da educação infantil como primeira etapa da educação básica. A diversidade de situações, com as suas disparidades e desigualdades, que se refletem em diferentes arranjos de políticas municipais, emprestam enorme complexidade à organização da oferta de educação infantil no país. Conhecimentos prévios evidenciam a existência de uma diversidade de profissionais (estatuto profissional), de relações de emprego e trabalho na área que precisariam ser conhecidas, no intuito de construirmos uma espécie de mapa do emprego e trabalho na educação infantil hoje.

7 Alguns trabalhos sobre a história dos jardins de infância no Brasil foram produzidos, citando-se, por exemplo, Moysés Kuhlmann Júnior (1998; 2000) e Gizele de Souza (2004; 2010).

8 A título de exemplificação, vale citar o trabalho de dissertação de mestrado de Elisângela Mantagute sobre a história das creches públicas municipais da rede de Curitiba, entre 1977 a 1986. Neste estudo, a autora analisa a forma de contratação das educadoras à época e as representações sobre o trabalho nas creches pelos gestores municipais. 


\section{Composição dos professores da educação infantil}

Uma característica básica da força de trabalho na educação infantil é o fato de se constituir em uma ocupação de gênero feminino. No Brasil, 97\% dos professores que atuam nessa etapa do ensino são mulheres (BRASIL, 2009b).

As estatísticas educacionais divulgadas pelo INEP, em 2009, informam a presença de 336.186 pessoas ocupando funções docentes em creches e pré-escolas, nas instituições de ensino públicas e privadas, divididas nas mencionadas categorias de particulares, filantrópicas, comunitárias e confessionais. Essas instituições de ensino respondem pela matrícula de 6.719.261 milhões de crianças de idades que variam de zero a nove anos e mais, o que significa $12,3 \%$ do total de matrículas na educação básica. As creches (para crianças de zero a três anos) acolhem 20,4\% das matrículas da educação infantil.

De acordo com a Sinopse sobre Professores da Educação Básica no Brasil (BRASIL, 2009b), que sistematiza dados do Censo Escolar de 2007, as redes públicas e privadas somam 1.882 .961 professores, sendo que $81,9 \%$ são mulheres. Desse total de professores que atuam na educação básica, 17,9\% encontram-se na educação infantil. Nas creches trabalham 95.643 pessoas e nas pré-escolas, 240.543. Nessa etapa do ensino, a presença de mulheres supera a encontrada em toda a educação básica. Na creche, $97,9 \%$ são mulheres, e na pré-escola $96,1 \%$.

Mais de $50 \%$ do professorado na educação infantil apresenta idades que variam entre 25 a 40 anos de idade, conforme se visualiza na Tabela 2.

TABELA 2 - NÚMERO DE PROFESSORES DA CRECHE E PRÉ-ESCOLA, POR FAIXA ETÁRIA - BRASIL, 2007

\begin{tabular}{c|c|c|c|c|c|c}
\hline & \multicolumn{6}{c}{ Idade } \\
\cline { 2 - 7 } & Total & Até 24 anos & $\begin{array}{c}25 \text { a 32 } \\
\text { anos }\end{array}$ & $\begin{array}{c}33 \text { a 40 } \\
\text { anos }\end{array}$ & $\begin{array}{c}41 \text { a 50 } \\
\text { anos }\end{array}$ & $\begin{array}{c}\text { mais de 50 } \\
\text { anos }\end{array}$ \\
\hline Creche & 95.643 & 11.977 & 31.701 & 25.264 & 20.345 & 6.356 \\
$\%$ & 28,4 & 12,52 & 33,14 & 26,41 & 21,27 & 6,64 \\
Pré-escola & 240.543 & 22.006 & 78.109 & 69.896 & 56.147 & 14.385 \\
$\%$ & 71,6 & 9,14 & 32,47 & 29,05 & 23,34 & 5,98 \\
\hline
\end{tabular}

FONTE: Brasil, MEC, Inep, Sinopse do Professor, 2009.

Estudo divulgado recentemente sobre professores no Brasil (GATTI; BARRETO, 2009) mostrou que, no âmbito da educação básica, a educação infantil concentra os professores mais jovens, não brancos e com menor escolaridade.

Relativamente à escolaridade constata-se a predominância de professoras formadas em nível de ensino médio na modalidade Normal. Mas, conforme podemos verificar na Tabela 3 , existem diferenças em relação às creches e pré- 
-escolas, e às regiões do país ${ }^{9}$. Há mais professoras com a formação de nível superior no Sudeste e na pré-escola. Prevalecem as que possuem a formação de nível médio no Nordeste e na creche. A consulta à série histórica das estatísticas sobre formação dos docentes na educação infantil, desde 2000, mostra que houve alteração no quadro da formação, crescendo o número de docentes licenciados em nível de ensino superior, diminuindo os que possuem apenas o ensino fundamental, seja completo ou incompleto. Isso vem sendo analisado como importante avanço na qualidade do atendimento, sendo convergentes os resultados de pesquisas que mostram que a formação do profissional é condição indispensável para uma educação infantil de qualidade, entendida como uma efetiva política de bem-estar e de educação. Revela também uma aproximação da oferta pública e privada com o quadro regulatório normativo.

TABELA 3 - PROPORÇÃO DE PROFESSORES NA EDUCAÇÃO BÁSICA E NA EDUCAÇ̃̃O INFANTIL (CRECHE E PRÉ-ESCOLA), DE ACORDO COM A ESCOLARIDADE - BRASIL E REGIÃO GEOGRÁFICA (NORDESTE E SUDESTE), 2007

\begin{tabular}{|c|c|c|c|c|c|c|c|}
\hline \multirow[b]{3}{*}{$\begin{array}{l}\text { Brasil e } \\
\text { região } \\
\text { geográfica }\end{array}$} & \multirow[b]{3}{*}{\begin{tabular}{|l} 
Nível e \\
etapa de \\
ensino
\end{tabular}} & \multirow[b]{3}{*}{$\begin{array}{c}\text { Total de } \\
\text { professores }\end{array}$} & \multicolumn{5}{|c|}{ Escolaridade } \\
\hline & & & \multirow[b]{2}{*}{$\begin{array}{c}\text { Fundamen- } \\
\text { tal } \%\end{array}$} & \multicolumn{2}{|c|}{ Ensino médio } & \multicolumn{2}{|c|}{ Superior } \\
\hline & & & & $\begin{array}{c}\text { Normal/ } \\
\text { Magistério } \\
\%\end{array}$ & $\begin{array}{l}\text { Ensino } \\
\text { médio \% }\end{array}$ & $\begin{array}{l}\text { Com licen- } \\
\text { ciatura \% }\end{array}$ & $\begin{array}{l}\text { Sem licen- } \\
\text { ciatura } \%\end{array}$ \\
\hline & $\begin{array}{l}\text { Educaçãc } \\
\text { básica }\end{array}$ & & & & & & \\
\hline Brasil & & 1.882 .961 & 0,84 & 25,20 & 5,48 & 61,64 & 6,76 \\
\hline Nordeste & & 570.647 & 1,47 & 41,43 & 6,42 & 44,87 & 5,79 \\
\hline \multirow[t]{2}{*}{ Sudeste } & & 741.604 & 0,28 & 15,70 & 4,54 & 72,06 & 7,38 \\
\hline & Creche & & & & & & \\
\hline Brasil & & 95.643 & 3,02 & 44,98 & 9,89 & 37,19 & 4,89 \\
\hline Nordeste & & 20.315 & 5,03 & 57,32 & 12,65 & 20,00 & 4,92 \\
\hline \multirow[t]{2}{*}{ Sudeste } & & 44.523 & 1,70 & 43,38 & 7,38 & 42,75 & 4,75 \\
\hline & Pré-escol & & & & & & \\
\hline Brasil & & 240.543 & 1,34 & 41,33 & 6,16 & 45,54 & 5,69 \\
\hline Nordeste & & 76.845 & 2,55 & 59,53 & 8,24 & 24,81 & 4,80 \\
\hline Sudeste & & 97.918 & 0,38 & 30,35 & 4,22 & 59,26 & 5,77 \\
\hline
\end{tabular}

FONTE: Brasil, MEC, INEP, Sinopse do Professor, 2009.

9 O Brasil é dividido em 5 grandes regiões geográficas: Norte, Nordeste, Centro-Oeste, Sudeste e Sul. As regiões Norte e Nordeste são as que apresentam os piores indicadores de condições de vida do país. As regiões Sudeste e Nordeste são as mais populosas do país, e as comparações entre elas exemplificam as desiguais distribuições de renda e acesso aos bens materiais e culturais no Brasil. 
O artigo 62 da referida LDBEN, o qual trata da formação dos profissionais da educação, estabelece:

\begin{abstract}
A formação de docentes para atuar na educação básica far-se-á em nível superior, em curso de licenciatura, de graduação plena, em universidades e institutos superiores de educação, admitida, como formação mínima para o exercício do magistério na educação infantil e nas quatro primeiras séries do ensino fundamental, a oferecida em nível médio, na modalidade Normal.
\end{abstract}

Evidencia-se nesse enunciado o estabelecimento de um patamar básico, a conclusão da educação básica e a qualificação em Magistério, sem o qual não é aceitável o exercício da função docente nos estabelecimentos educacionais de educação infantil. Além disso, a formação de professores da educação básica no Brasil tem se alterado nos últimos anos relacionando-se com as exigências crescentes de qualificação dos profissionais em níveis cada vez mais elevados de escolaridade. Atualmente, a formação inicial para atuação nas séries iniciais do ensino fundamental e na educação infantil começa a ocorrer no âmbito das universidades e instituições de ensino superior, de acordo com as novas diretrizes curriculares para os cursos de Pedagogia. Presenciamos também a existência de cursos, segundo a modalidade de ensino a distância, destinados aos professores em serviço que não possuem formação de Magistério e que estão inseridos nas redes públicas e conveniadas de educação infantil.

As informações e estudos que enfocam a formação dos profissionais da educação infantil evidenciam, no entanto, que a licenciatura em nível de ensino superior vem sendo oferecida, em razão de forte demanda aberta pelo acesso ao ensino médio e da necessidade de cumprimento de metas estabelecidas na legislação educacional, predominantemente por instituições de ensino privadas, em cursos de curta duração (em geral, na modalidade de Normal Superior), de orientação pragmática, sem o adensamento teórico necessário a uma atuação profissional consistente, não significando necessariamente uma formação de qualidade (CAMPOS, 2008).

Outras informações relevantes para compor um quadro da situação do trabalho na área não são disponibilizadas de forma desagregada pelas estatísticas educacionais. Por exemplo, não estão disponibilizadas informações sobre outros profissionais não docentes, que se ocupam de grupos de crianças, executando trabalho similar aos professores, exercendo funções pedagógicas, segundo se pode conhecer por meio de observações e estudos em andamento. Apesar de serem produzidas, não são divulgadas ainda informações desagregadas sobre 
os profissionais das diferentes redes de ensino, não sobressaindo os dados sobre os respondentes das instituições comunitárias, filantrópicas e confessionais nos Censos Escolares. Existe necessidade de que as informações quantitativas evidenciem um quadro mais preciso da formação e do trabalho no campo do cuidado e educação da primeira infância no país.

\section{Situações de trabalho e emprego em Belo Horizonte}

Belo Horizonte é capital de Minas Gerais, estado situado na região sudeste do Brasil. Tem população aproximada de 2 milhões e duzentos mil habitantes. De acordo com resultados preliminares do Censo Escolar de 2009 (BRASIL, 2009a), a cidade apresenta matrícula de 567.637 alunos na educação básica, divididos nas redes de ensino pública e privada. Desse total de alunos, 63.607 estão na educação infantil, frequentando 49 Unidades Municipais de Educação Infantil - UMEIs, 13 escolas municipais de educação infantil (pré-escolar), classes de educação pré-escolar que funcionam em escolas municipais de ensino fundamental, escolas infantis da rede estadual de ensino e, aproximadamente 800 creches/pré-escolas privadas. Nessa etapa do ensino, as matrículas ainda estão concentradas na rede privada de ensino $(72,4 \%)$. O crescimento das matrículas públicas municipais é observado com a criação das UMEIs somente a partir de 2004.

A rede privada é constituída de uma multiplicidade de instituições: particulares com fins lucrativos, comunitárias e filantrópicas, com características diversas em relação à capacidade de atendimento, localização, capacidade de manutenção financeira, condições materiais de infraestrutura, quadro de pessoal, organização e condições de trabalho. Dentre essas instituições existem aquelas que possuem caráter confessional. Uma parte significativa das instituições comunitárias e filantrópicas recebe recursos públicos municipais, que são repassados após o estabelecimento de um termo jurídico, caracterizando uma relação de conveniamento, segundo o Direito Administrativo. Essa modalidade de ação pública, que subsidia uma oferta de serviços de caráter privado comunitário/ filantrópico de educação infantil, é antiga em Belo Horizonte, existindo desde a primeira metade dos anos 1980, vinculada à Secretaria de Assistência Social. Origina-se, portanto, como política de assistência social. Em 2002, a gestão dos 
convênios foi transferida para a Secretaria Municipal de Educação. A passagem da administração dos convênios da assistência social para a educação é uma das características das políticas municipais de educação infantil na atualidade e se constitui em um dos pontos de tensão na política educacional brasileira.

Atualmente, os convênios abrangem 198 instituições comunitárias/filantrópicas que são responsáveis pelo atendimento de aproximadamente 21.700 crianças, na faixa de idade de menor que um ano a 5 anos de idade. Nessas instituições, $84 \%$ das crianças, concentradas na faixa de idade de 3 a 5 anos e 8 meses (significando $73 \%$ do atendimento), são acolhidas em jornada de tempo integral. A matrícula nessas instituições conveniadas é muito significativa, perfazendo $47 \%$ das matrículas privadas oferecidas em Belo Horizonte.

$\mathrm{Na}$ rede municipal de ensino de Belo Horizonte são atendidas aproximadamente 15 mil crianças, na faixa de idade de 0 a 5 anos e 8 meses. Apenas $11 \%$ estão na faixa de idade de 0 a 3 anos, sendo que somente essas são acolhidas em jornada de tempo integral. Sendo assim, nas instituições conveniadas é onde as crianças permanecem mais tempo em todas as faixas etárias.

A seguir apresentamos as informações relativas ao ingresso, contrato de trabalho, cargos, salários e carreira, condições gerais de trabalho e vinculações sindicais dos trabalhadores na rede pública municipal e nas instituições conveniadas. Tendo em vista a insuficiência de informações sobre instituições particulares com fins lucrativos nas fontes pesquisadas, apenas serão apresentadas informações sobre ingresso e vinculação sindical.

Acompanhando a tendência de muitos municípios brasileiros, a expansão das matrículas públicas em Belo Horizonte, predominantemente por meio da criação das UMEIs, implicou na criação de um novo cargo público na área da educação, o cargo do educador infantil. Consiste na implantação de uma nova carreira profissional, dentro da educação, mas diferente da tradicional carreira do magistério público, formada pelos docentes que atuam no ensino fundamental e médio. $\mathrm{O}$ ingresso na rede pública municipal dos educadores infantis acontece por concurso público de provas e títulos, tal como para os professores da carreira do magistério público. Para o educador exige-se habilitação em Magistério, nível de ensino médio. No entanto, mais de $60 \%$ dos que estão atualmente em exercício possuem formação em nível de ensino superior - Pedagogia.

Foram encontradas diferenças salariais entre essas duas categorias de trabalhadores da educação básica no setor público municipal. Na Tabela 4, a seguir, pode-se visualizar que o salário inicial do educador infantil significa $47 \%$ do vencimento atribuído ao professor municipal no início e no final da carreira. 
VIEIRA, L. F; SOUZA, G. Trabalho e emprego na educação infantil no Brasil: segmentações...

TABELA 4 - VENCIMENTOS DAS CLASSES DE PROFESSOR E EDUCADOR INFANTIL NA REDE MUNICIPAL DE EDUCAÇÃO DE BELO HORIZONTE. VIGÊNCIA A PARTIR DE $01 / 11 / 2008$

\begin{tabular}{cccc}
\hline \multicolumn{4}{c}{ Vencimento (R\$) } \\
\hline Nível & Professor & Educador infantil \\
\hline $10^{*}$ & Piso salarial & Nível & Piso salarial \\
11 & 1473,76 & 1 & 850,00 \\
12 & 1547,45 & 2 & 892,50 \\
13 & 1624,82 & 3 & 937,13 \\
14 & 1706,06 & 4 & 983,98 \\
15 & 1791,37 & 5 & 1033,18 \\
16 & 1880,94 & 6 & 1084,84 \\
17 & 1974,98 & 7 & 1139,08 \\
18 & 2073,73 & 8 & 1196,04 \\
19 & 2177,42 & 9 & 1255,84 \\
20 & 2286,29 & 10 & 1318,63 \\
21 & 2400,60 & 11 & 1384,56 \\
22 & 2520,63 & 12 & 1453,79 \\
23 & 2646,66 & 13 & 1526,48 \\
24 & 2779,00 & 14 & 1602,80 \\
\hline
\end{tabular}

FONTE: PBH/ Secretaria Municipal Adjunta de Recursos Humanos/SMED/GEOE - outubro/2008, apud Pinto (2009).

NOTA: *A progressão na carreira por habilitação para professores de $1^{\circ}$ e $2^{\circ}$ ciclos é imediata em 10 níveis.

A progressão na carreira também acontece de forma diferenciada. O professor com habilitação em nível de ensino superior inicia a carreira imediatamente no nível 10. O educador necessita esperar 3 anos e finalizar o período de estágio probatório para progredir até no máximo 5 níveis. A cada 3 anos, após avaliação de desempenho, o educador pode progredir um nível. Assim, ele só acederá ao último nível da carreira se possuir nível superior, após 30 anos de trabalho.

As 1.850 educadoras infantis, em exercício no período desta pesquisa, reportam-se ao SindREDE, Sindicato de Professores da Rede Municipal de Ensino, que é o órgão de representação sindical de defesa dos interesses da categoria dos professores, criado no final dos anos 1980. 
Nas instituições conveniadas, as pessoas que exercem função docente são contratadas como "educadoras" ou "monitoras" e o ingresso não acontece por meio de concurso. O recrutamento é realizado por indicação ou seleção. O convênio com o poder público municipal estabelece algumas condições: é necessário que os trabalhadores possuam vínculo formal de trabalho, regido pela Consolidação das Leis do Trabalho - regime de contrato CLT, sendo também exigida, para os que assumem função pedagógica, a comprovação de formação em curso de Magistério, no mínimo de nível médio. Na carteira de trabalho consta a função: educadora ou monitora. Raramente professora. E não existe carreira ou possibilidades de progressão por tempo de trabalho ou comprovação de titulação. Os postos de trabalho vinculados ao trabalho pedagógico são basicamente os de coordenador pedagógico e monitor/educador.

Os trabalhadores das instituições comunitárias e filantrópicas reportam-se ao Sindicato dos Empregados em Entidades Culturais, Recreativas, de Assistência Social, de Orientação e Formação Profissional do estado de Minas Gerais - SENALBA. As faixas salariais são definidas em dissídio coletivo. Essas instituições são aconselhadas a não registrar o trabalhador como professor, pois essa denominação relaciona-se com outra categoria trabalhista, vinculada a outro sindicato, podendo esse procedimento gerar processos na Justiça do Trabalho, o que onera a gestão das instituições comunitárias/filantrópicas.

Com efeito, o professor da rede privada possui sindicato próprio, que é o Sindicato de Professores do estado de Minas Gerais - SINPRO/MG, que delibera em dissídio coletivo faixas salariais mais elevadas que o SENALBA, correspondendo a condições de jornada de trabalho também diversas.

A maioria das educadoras/monitoras das instituições de educação infantil comunitária e filantrópica recebe salários que variam entre 1 a 2 salários mínimos, cujo valor vigente (março/2009 a dezembro/2009) é de $\mathrm{R} \$ 465,00$ (quatrocentos e sessenta e cinco reais). Esse valor significa, no câmbio atual, aproximadamente 250 dólares. Essa faixa salarial varia conforme o porte da instituição: nas instituições com menor capacidade de atendimento, em geral situadas em comunidades mais pobres, identificadas na tipologia comunitária, os salários das educadoras nunca ultrapassam dois salários mínimos. Naquelas instituições de maior porte, identificadas como filantrópicas, os salários praticados ultrapassam dois salários mínimos podendo chegar a três/quatro.

A relação entre jornada de trabalho e salário também é diferente se comparamos o atendimento público e privado conveniado. As educadoras infantis da Prefeitura trabalham 4 horas e trinta minutos por dia, cinco vezes por semana. No seu salário está incluído um tempo para planejamento de suas atividades. Nas instituições conveniadas as coordenadoras pedagógicas e as monitoras/ 
educadoras trabalham oito horas por dia, sem contar com tempo remunerado para planejamento do seu trabalho.

Os resultados brevemente apresentados revelam não só diferenças, mas desigualdades nas situações de trabalho e emprego na educação infantil em Belo Horizonte. Não é demais lembrar que essa situação é ilustrativa da realidade brasileira. As diferenças salariais também observadas nos contratos e nas condições de trabalho entre as instituições de educação infantil, conforme a sua tipologia, também são constatadas em sua relação com as outras etapas da educação básica. Na educação infantil estão concentradas as maiores proporções dos que recebem os salários mais baixos e os que praticam as mais extensas jornadas de trabalho semanais (BRASIL, 2007; GATTI; BARRETO, 2009; SOUZA; GOUVEIA; SOUZA, 2010).

\section{Considerações finais}

A descentralização da gestão das políticas educativas, por meio da municipalização, enseja enorme diversidade na organização dos sistemas e redes municipais de ensino. Os diferentes arranjos das políticas municipais observados evidenciam a existência de uma multiplicidade de profissionais com status e formação/qualificação diferenciados, bem como variadas modalidades de relações de emprego e trabalho que, em geral, reiteram a precarização do trabalho docente na educação infantil. Simultaneamente, observa-se a demanda por crescente profissionalização do campo.

Em Belo Horizonte, observa-se processo de precarização no exercício profissional na educação infantil. No setor público municipal presencia-se a criação de novos postos de trabalho fora da carreira do magistério público, com salários menores e menores oportunidades de progressão pelas características da carreira pública. Foram observadas maiores jornadas de trabalho na rede privada conveniada com o poder público, salários ainda mais baixos e inexistência de carreiras.

De forma mais acentuada que nas demais etapas da educação básica, a educação infantil constitui-se como um locus por excelência de diversidade de formas de composição e organização do trabalho docente. Colaboram para isso os processos e origens históricas das instituições de educação infantil, a composição nos municípios de instituições públicas e privadas (organizações comunitárias, filantrópicas etc.), a presença, em muitas redes, de uma estrutura dual na composição do corpo docente - professores pertencentes à carreira do 
magistério e auxiliares de sala vinculados aos chamados quadros da carreira civil, além da diversidade de terminologias e denominações dos grupos de profissionais que atuam na educação infantil.

Além disso, é possível constatar a necessidade de pesquisas sobre trabalho e emprego na educação infantil, articulando informações relativas às etapas e modalidades da educação básica.

Gostaríamos de sugerir finalmente, após trazer alguns resultados de pesquisa, que avançar na formação e na valorização profissional da professora ou educadora da educação infantil implicaria, entre outras tarefas, enfrentar a concepção e o modelo que "naturaliza" a função docente, "barateando" ou "desqualificando" o trabalho realizado nesse contexto. Isso poderia ter consequências positivas para a construção de carreiras docentes para fazer frente ao desafio da expansão, sobretudo pública, de uma educação infantil de qualidade, que tenha como meta não reproduzir desigualdades sociais, de gênero ou raça/cor.

\section{REFERÊNCIAS}

BALL, Stephen J. Grandes políticas, um mundo pequeno: introducción a una perspectiva internacional em lãs políticas educativas. In: NARODOWSKI, M.; NORES, M.; ANDRADA, M. (Orgs). Nuevas tendências em políticas educativas: Estado, mercado y escuola. Buenos Aires: Granica, 2002.

BRASIL. Ministério da Educação. Instituto Nacional de Pesquisas Educacionais "Anísio Teixeira". Resultados preliminares do Censo Escolar de 2009. Brasília, 2009a. Disponível em: $<\mathrm{http} / / \mathrm{www}$.inep.gov.br>.

Sinopse Estatística do Professor da Educação Básica. Brasília, 2009b. Disponível em: $<$ http//www.inep.gov.br $>$.

BRASIL. Ministério do Trabalho e do Emprego. Relação Anual de Informações Sociais (RAIS). Programa de Disseminação de Estatísticas do Trabalho. Brasília, 2007. Disponível em: $<$ http//www.mte.gov.br>.

CAMPOS, Maria Malta. Educar e cuidar: questões sobre o perfil do profissional da educação infantil. In: BRASIL. Ministério da Educação e do Desporto. SEF/DPE/ COEDI. Por uma política de formação do profissional de educação infantil. Brasília, 1994.

CAMPOS, Roselane. Trabalho docente e formação de professores da educação infantil. In: SEMINÁRIO DA REDESTRADO “NUEVAS REGULACIONES EN AMÉRICA 
VIEIRA, L. F; SOUZA, G. Trabalho e emprego na educação infantil no Brasil: segmentações...

LATINA", 7., Buenos Aires, 2008. Anais... (1 CD-ROM).

FANFANI, E. T. La condición docente. Buenos Aires: Siglo Veintiuno, 2005.

GATTI, B. A. (Coord.); BARRETO, E. S. Professores do Brasil: impasses e desafios. Brasilia: UNESCO, 2009.

KUHLMANN JÚNIOR, Moysés. Infância e educação infantil: uma abordagem histórica. Porto Alegre: Mediação, 1998.

KUHLMANN JÚNIOR, Moysés. Educando a infância brasileira. In: LOPES, E.; FARIA FILHO, L.; VEIGA, C. (Orgs). 500 anos de educação no Brasil. Belo Horizonte: Autêntica, 2000, p. 469-496.

MANTAGUTE, Elisângela Iargas Luzviak. Educar a Infância: estudo sobre as primeiras creches públicas da rede municipal de educação de Curitiba (1977-1986). Dissertação (Mestrado) - Programa de Pós-Graduação em Educação da UFPR, Curitiba, 2008.

MOSS, Peter. Structures, understandings and discourses: possibilities for re-envisioning the early childhood worker. Contemporary Issues in Early Childhood, v. 7, n. 1, 2006.

OLIVEIRA, Dalila A. A reestruturação do trabalho docente: precarização e flexibilização. Educação \& Sociedade, v. 25, n. 89, p. 1127-1144, dez. 2004.

PINTO, Mércia F. N. O trabalho docente na educação infantil pública em Belo Horizonte. Dissertação (Mestrado) - Faculdade de Educação, UFMG, Belo Horizonte, 2009.

ROSEMBERG, Fúlvia. Expansão da educação infantil e processos de exclusão. Cadernos de Pesquisa, São Paulo, n. 107, p. 7-40, jul. 1999.

ROSEMBERG, Fúlvia. Organizações multilaterais, Estado e políticas de educação infantil. Cadernos de Pesquisa, São Paulo, n. 115, p. 25-63, mar. 2002.

SILVA, Isabel O. Profissionais da educação infantil: formação e construção de identidades. São Paulo: Cortez, 2001.

. Trabalho docente na educação infantil: dilemas e tensões. In: REUNIÃO ANUAL DA ANPED, GT 07, 30., Caxambu, 2007. Anais... Disponível em: <www. anped.org.br>.

SOUZA, Gizele de. Instrução, o talher para o banquete da civilização: cultura escolar dos jardins-de-infância e grupos escolares no Paraná, 1900-1929. Tese (Doutorado) 
- Programa de Estudos Pós-Graduados em Educação: História, Política, Sociedade. PUC/SP, São Paulo, 2004.

SOUZA, Gizele de. Os jardins de infância públicos do século XX. In: SOUZA, Gizele de (Org.). Educar na infância: perspectivas histórico-sociais. 1 ed. São Paulo: Contexto, 2010, v. 1, p. 123-140.

SOUZA, Ângelo R.; GOUVEIA, Andréa B.; SOUZA, Gizele. Os professores da educação infantil no Brasil: perfil e demandas. In: ENDIPE, 15., Anais... Belo Horizonte: UFMG, 2010.

TARDIF, M.; LESSARD, C. O trabalho docente: elementos para uma teoria da docência como profissão. 3. ed. Petrópolis: Vozes, 2007.

VIEIRA, Lívia M. F. Creches no Brasil: de mal necessário a lugar de compensar carências. Rumo à construção de um projeto educativo. Dissertação (Mestrado) Faculdade de Educação, UFMG, Belo Horizonte, 1986.

VIEIRA, Lívia M. F. A formação do profissional da educação infantil no Brasil no contexto da legislação, das políticas e da realidade do atendimento. Pro-Posições, Campinas, v. 10, n. 1 (28), p. 28-39, mar. 1999.

VIEIRA, L. M. V.; MESQUITA, A.; PINTO, M.; BATISTA, C.; RAGO, D. Trabalho e emprego na educação infantil em Belo Horizonte: relatório de pesquisa. Belo Horizonte: UFMG (Bolsa de Pesquisa PROBIC-FAPEMIG), jul. 2009. 60 p. (mimeo)

VIEIRA, L. M. F.; SILVA, Carla F. F. Políticas municipais de educação infantil: o que dizem as pesquisas na Universidade. Relatório de Pesquisa. Belo Horizonte: UFMG (Bolsa de Pesquisa FUNDEP-SANTANDER), ago. 2009. 70 p. (mimeo)

Texto recebido em fevereiro de 2010.

Texto aprovado em junho de 2010. 